\title{
Praktyk
}

\section{Publikasiegereed? \\ Oor die aanbiedingswyse, keuringsprosedure en teksversorging van navorsingsartikels ${ }^{1}$}

Mariana Venter

Buro vir Wetenskaplike Tydskrifte

Potchefstroomse Universiteit vir $\mathrm{CHO}$

POTCHEFSTROOM

E-pos: bwtmv@puknet.puk.ac.za

Abstract

Ready to publish? On the presentation, refereeing process and text editing of scholarly articles

This article is an attempt to present authors planning to write a scholarly article with practical guidelines for submitting the article to a specific journal. The following aspects are also discussed: typical points of criticism usually raised in referees' reports, and the necessity for clarity of expression and lucid scholarly style. Specific examples of how to enhance the technical and language finish of an article are included. This article is the outcome of many years of practical work within the Bureau for Scholarly Journals; hence the publication of it in Literator, one of the journals processed by the Bureau.

Die uitsluitlike doel van hierdie bydrae is om op praktykgerigte wyse wenke deur te gee - wenke wat moontlik kan bydra tot 'n bewusmaking van sekere aspekte van artikelskryf. Want om 'n artikel "publikasiegereed" te kry, veronderstel 'n veelheid insette.

Die aanpak en aanbiedingswyse wat in dié artikel gevolg word, is egter nie primêr akademies nie. Eerder moet dit gesien word as enkele

$1 \quad$ Verwerkte weergawe van 'n bydrae wat deel gevorm het van twee paneelbesprekings oor die skryf van navorsingsartikels. Hierdie byeenkomste was gereël deur die Navorsingskomitee en die Onderrigkomitee (Fakulteit Lettere en Wysbegeerte - PU vir $\mathrm{CHO}$ ) en is in 2001 aangebied op die Potchefstroom- en Vaaldriehoekkampus van die $\mathrm{PU}$ vir $\mathrm{CHO}$. 
gedagtes wat voortgespruit het uit die stiplees, herlees en teksversorging van artikels wat oor 'n tydperk van dertien jaar vir drie vaktydskrifte aangebied is. Voorbeelde wat gebruik word, het die praktyk self verskaf.

Omdat hierdie teksversorging en wat daarmee gepaard gaan, onder andere vorm aangeneem het teen die agtergrond van keurderskommentaar wat gelewer is op honderde navorsingsartikels, word algemene aspekte van tipiese keurderskommentaar ook aangeraak. Insae in so 'n groot gemene deler van kritiekpunte kan die voornemende skrywer help in die beplande aanbiedingswyse van artikels omdat moontlike negatiewe keurderskommentaar vooraf uitgeskakel kan word.

Aspekte wat vervolgens in hierdie artikel aangeraak word, is dus die volgende:

- Wenke vir die publikasievoorbereiding van 'n navorsingsartikel nog vóór dit aan 'n vaktydskrif voorgelê word.

- Tipiese keurderskommentaar wat voorkom kan word.

- Hoe gepoog kan word om die stelwyse helder en verstaanbaar te hou.

- Enkele spesifieke foute wat uitgeskakel kan word.

1. Wenke by die voorbereiding van 'n manuskrip voordat dit vir keuring aan 'n tydskrif gestuur word

\subsection{Lees die tydskrif se "Voorskrifte vir skrywers" baie noukeurig}

- Vra die tydskrif waarin jy graag wil publiseer se "Voorskrifte vir skrywers"/"Style sheet" aan. In die voorskrifte word dikwels inligting gegee oor die aanbiedingswyse en die aard van die artikels.

- Lees ook die inhoudsopgawes van 'n paar jaargange van die tydskrif waarin jy wil publiseer. Tydskrifte indekseer dikwels 'n jaargang se artikels onder trefwoorde of artikeltitels. Lees dit aandagtig. So 'n voëlvlug oor 'n paar jaar se artikels gee dikwels 'n aanduiding van die aard van artikels wat 'n spesifieke tydskrif graag publiseer.

\subsection{Skenk aandag aan die formulering van die titel}

Die titel van 'n artikel is die leser se eerste inklimplek in die artikel. Jy wil immers hê dat die artikel gelees word. 'n Prikkelende en fyn geformuleerde titel kan 'n leser stimuleer om die artikel te lees. Jou titel moet reklamewaarde hê anders gaan niemand dit lees nie. En verder: as die titel 'n besliste en afgebakende invalshoek het, weet die leser dadelik waaroor dit gaan. 
As jy dus die stof wat jy in die artikel wil behandel, reeds afgebaken het, bedink 'n gepaste titel. As jy finaal op 'n titel besluit het, vra jouself die volgende vrae:

- Dek die vlag die lading? Met ander woorde: word die lesersverwagting wat deur die titel geskep word, deur die artikel self ondersteun?

- Is dit titel selfverduidelikend? Sou 'n subtitel die leser nie kon help om agter te kom waaroor die artikel handel nie?

- 'n Titel wat te wyd en te algemeen geformuleer is, sal geen leser se belangstelling prikkel nie

\section{Voorbeelde}

- 'n Titel wat te wyd en algemeen geformuleer is:

"Onderwys in die nuwe Suid-Afrika"

- 'n Meer afgebakende titel kon byvoorbeeld lui:

"Rekenaargesteunde onderwys in die nuwe SA"

- 'n Titel wat 'n spesifieke fokuspunt het, kon dalk so gestel word:

"Rekenaargesteunde onderwys vir taalonderrig aan hoërskoolleerlinge"

- Waak daarteen dat die titel nie soveel inligting bevat dat dit verwarrend word nie. Kyk die volgende voorbeeld:

"Die betekenis van konsepte in die Opvoedkunde met verwysing na teoretiese diversiteit met betrekking tot enkele pedagogies-antropologiese standpuntverskille"

- 'n Titel moet ook nie te lank wees nie Kyk byvoorbeeld na die volgende titel wat 'n artikelskrywer gekies het:

"Kan die Suid-Afrikaanse Nasionale Weermag sy plig wat grondwetlik bepaal is in die konteks van vandag se omstandighede nakom?"

\section{Kommentaar:}

Afgesien van die formulering wat verkort kan word, sou hierdie titel as dit in 'n groter lettertipe en as titel geformateer moet word, oor bykans drie reëls strek. Boonop is so 'n bladspieël ook effens steurend op die oog. 'n Moontlikheid om die probleme met 'n titel soos hierdie te oorkom, is om die titel te verkort en 'n deel van die vraag wat in die oorspronklike titel gestel is, in ' $n$ inleidende paragraaf te inkorporeer. Of dit die ideale oplossing is, kan gedebatteer word, maar inhoudelik 
het die informasie dieselfde gebly en is die bladspieël meer lesersvriendelik. Die herskrywing sou soos onderstaande gedoen kon word:

\section{Die Suid-Afrikaanse Weermag en sy grondwetlike plig (as titel)}

'n Vraag wat dikwels geopper word, is of die Nasionale Weermag sy grondwetlike plig in die konteks van vandag kan nakom. Op dié vraag kan moontlik só geantwoord word:

Die ... (bostaande gedeelte as inleidende paragraaf).

\section{'n Soortgelyke voorbeeld}

"Enkele perspektiewe aangaande die internasionale reg wat op die ouer-kindverhouding van toepassing is"

'n Korter titel met 'n inleidende sin soos onderstaande sou gebruik kon word:

"Die internasionale reg en ouer-kindverhoudings" (die titel)

Hierdie artikel bied enkele perspektiewe op ... ('n inleidende sin)

\subsection{Strukturering van stof}

- Struktureer die artikelstof en maak gebruik van subparagrawe met gepaste opskrifte - so 'n raamwerk is nie alleen 'n dissipline om jou gedagtes te sistematiseer en te orden nie - dit bied vir die leser van jou artikel ook 'n paar springklippe deur die rivier.

- As die leser byvoorbeeld net die paragraafopskrifte lees, het hy ook al 'n idee waaroor die artikel handel.

- Aan die ander kant, moet die artikel ook nie so opsnipper deur klein afdelinkies dat dit naderhand soos 'n notule lyk nie.

\subsection{Die inligting wat in die abstract gegee moet word}

Die abstract moet die artikelinhoud saamvat. Moet die abstract nie gebruik as 'n "inleiding" wat informasie gee wat nie in die artikel self aan die bod kom nie.

Doen moeite met die formulering van die abstract. Dit is die deel van 'n artikel wat in internasionale tydskrifindekse gebruik word. Laat die abstract vooraf taalversorg.

\subsection{Lengte van artikel}

Kyk vooraf wat die woordtelling van jou artikel is. Die tydskrif self het ook gewoonlik 'n voorgestelde bladsylengte vir artikels. Die meeste tydskrifte 
kan dit nie finansieel bekostig om daardie ekstra bladsye namens die outeur te subsidieer nie. En dit help nie om te kierang deur die artikel byvoorbeeld te formateer in 'n 10-punt sodat dit minder bladsye beslaan nie. As die tydskrifformateerder jou artikel op dieselfde wyse as ander artikels in 'n tydskrifnommer gaan formateer, sal die ekstra bladsye nie verdoesel kan word nie. Ook het die meeste fakulteite 'n afsnypunt vir die betaling van bladgeld. 'n Dekaan gaan nie baie vriendelik wees as jy aansoek doen om bladgeld van R1800 en die afsnypunt is R1000 nie.

\subsection{Bibliografiese styl; gebruik van bronne}

Baie van die dinge wat ek hier beklemtoon, mag dalk voor die hand liggend wees, maar dit veroorsaak dikwels agterna baie navrae en heenen-weerkorrespondensie wat tydrowend is en na albei kante irritasie veroorsaak.

- Kontroleer dat alle bronne waarna in die artikel self verwys word, in die bronnelys ingesluit is.

- Maak seker dat daar nie ekstra bronne is wat wel in die bronnelys genoem word, maar waarna nie in die artikel self verwys word nie. 'n Keurder sien hierdie "vertoon" van ekstra bronne as window dressing.

- Kruiskontroleer dat 'n bron se publikasiedatum in die artikel ooreenstem met die datum in die bibliografie. Dit is baie lastig as weersprekende verskyningsdatums eers weer later reggestel moet word.

- Maak seker dat alle bibliografiese inskrywings absoluut volledig is. Jy sal verbaas wees hoeveel tyd jy agterna moet bestee om weer eens biblioteek toe te gaan om onvolledige gegewens te gaan soek. Maak seker dat jy alle besonderhede van tydskrifartikels, internetartikels, bydraes in versamelbundels, ensovoorts het. Onvolledige bibliografiese besonderhede is een van die dinge wat die publikasiegereedmaking van 'n artikel die meeste kan vertraag.

- Maak seker dat die bibliografiese inskrywings geformateer is in die bibliografiese styl van die tydskrif self. Kyk na die voorbeelde van bibliografiese inskrywings: hoofletters wanneer dit hoofletters moet wees, kursiewe druk waar dit kursiewe druk moet wees. Baie afhandelingstyd en agterna-irritasie kan uitgeskakel word indien die artikel uit die hek uit reg geformateer word.

\subsection{Formatering van die artikel}

- Die tydskrifpersoneel sal jou artikel keurig probeer formateer. Volg egter sover moontlik die formateringswyse wat in die tydskrif gebruik 
word (bv. die lettertipe, voorkeure ten opsigte van die gebruik van kursief of vetdruk, die gebruik van voetnote, al dan nie, ens.). Inligting hieroor staan dikwels ook in die "Voorskrifte vir skrywers"/ "Style sheet".

- As grafika in die artikel gebruik, maak vooraf seker dat dit in die formaat is wat die tydskrif verkies.

- Save jou artikel as 'n doc.lêer en nie as byvoorbeeld text only nie.

\section{Oor die keuringsproses}

\subsection{Handhaaf anonimiteit}

Artikels word gewoonlik anoniem na keurders gestuur. Ter wille van objektiewe keuring, moet jy jouself ook nie in die artikel op allerlei wyses identifiseer nie.

- Vermy byvoorbeeld 'n sin soos die volgende: "By die Potchefstroomse Universiteit is 'n navorsingsprojek geloods oor 'Skadelike afvalstowwe'. Ekself (MV) was verantwoordelik vir die sistematisering van die empiriese gegewens". Ten eerste het jy nou al verklik aan watter universiteit jy verbonde is, die onderwerp verraai dat dit waarskynlik uit die Department Chemie kom en die parafering na "ek" kan jou moontlik volledig identifiseer.

- Laat ook aanvanklik daardie voetnoot op bladsy een waarin jy die titel van jou proefskrif en jou promotor of studieleier se naam noem. So ook jou eie naam en universiteit aan die einde van die artikel. Hierdie gegewens kan in die finale weergawe wat gepubliseer gaan word, bygevoeg word.

\subsection{Die keuringsproses self}

'n Artikel word vir evaluering gewoonlik aan drie keurders gestuur sonder om die artikelskrywer se naam te vermeld. Die keurders weet ook nie die identiteit van die ander keurders nie. Vandat die artikel uitgestuur word totdat die artikelskrywer die kommentaar terugkry, duur enigiets van drie tot ses maande. Tydskrifredaksies beskik nie oor die middele om keurders te betaal nie en omdat 'n redaksie afhanklik en eintlik verleë is oor 'n keurders se insette, kan daar nie druk uitgeoefen word om verslae "gou" af te handel nie. 


\subsection{Samevattende keurdersverslag}

- Wanneer al drie keurders se keurderskommentaar terugontvang is, maak die redakteur 'n aanbeveling en word die keurders se kommentaar aan die outeur deurgegee.

- Alle artikels word terugverwys na die outeurs vir finale hersiening en redigering.

- In die saamstel van die keurderskommentaar word gepoog om nie kwetsende kritiek na die outeur deur te gee nie. As 'n keurder egter met goeie gronde negatief oor 'n artikel oordeel, is dit nie altyd moontlik om sy kritiek in sulke voeë te lê dat dit klink of die keurder die artikel eintlik aanprys nie.

\subsection{Tipiese keurderskommentaar}

As 'n mens al 'n hele aantal jare sulke keurdersverslae saamgestel het, val dit jou op dat die volgende kritiekpunte byna refreinagtig in keurdersverslae voorkom:

- Wat wil die skrywer eintlik sê?

- Die outeur sê nie wat hy met die artikel beoog nie.

- Die outeur maak aannames wat hy nie motiveer nie - sweeping statements.

- Die artikel weerspieël 'n eensydige en voorafingenome standpuntinname. Daar moet ook in gesprek getree word met voorstanders van ander uitgangspunte.

- Die outeur noem interessante feite, maar tree nie daarmee in gesprek nie.

- Wat is die outeur se eie standpunt?

- Die navorsing lyk verouderd. Die outeur is nie op hoogte met die nuutste vakliteratuur nie; te min resente bronne in die bibliografie.

- Te min resente tydskrifartikels oor die onderwerp is gebruik.

- Die artikel het nie 'n stewige teoretiese onderbou nie.

- Die argumentasielyn het "gate" - die logiese skakels in die opbou van die argument ontbreek hier en daar. Daar is spronge in die gedagtelyn.

- Te veel veronderstelde voorkennis word van die leser vereis.

- Die outeur se gevolgtrekkings is te algemeen en ontwikkel nie organies uit die voorafgaande beredenering nie. 
- Die stelwyse en formulering is hier en daar 'n leesbelemmering. Sinne moet korter wees.

- Die artikel bied nie 'n nuwe perspektief nie. Die navorsingsgegewe bied nie 'n eie en unieke bydrae tot die vakgebied nie.

Wat hierdie laaste kritiekpunt betref, probeer verhoed dat 'n keurder sy evaluering verwoord soos in die onderstaande nota wat 'n keurder saam met sy verslag gestuur het: "Hierdie artikel is soos om Marie-beskuitjies te eet; dit maak nie juis saak of dit Bakers Marie Biscuits of Blue Label of No Name Brand is nie; ' $n$ mens eet dit en vergeet gou hoe dit gesmaak het." So 'n uitwyding van die kant van 'n keurder impliseer natuurlik dat 'n artikel niks nuuts of verrassends gebring het nie.

Maak vooraf seker dat jou artikel nie 'n ope skyf word vir bostaande tipe opmerkings nie.

\section{Helderheid van formulering, stelwyse}

Naas inhoudelike veranderinge wat die artikelskrywer weer aanbring voordat sy artikel finaal as publikasiegereed aanvaar kan word, is daar ook aanpassings ten opsigte van stel- en aanbiedingswyse waarop 'n mens bedag moet wees.

\subsection{Algemeen}

- Wat formuleringswyse betref, is die stelreël: formuleer so duidelik en so ondubbelsinnig as moontlik! Geleerde vaktaal beïndruk niemand nie. 'n Mens skryf immers om verstaan te word.

\section{Voorbeelde}

'n Artikelskrywer wou waarskynlik sê dat 'n huisgesin wat bestaan uit ouers en kinders op grond van bloedbande van mekaar familie is. Ouers en kinders kan egter eers as 'n gesin getipeer kan word wanneer hulle ook deur ' $n$ liefdesband gebind word. Die ingewikkelde formulering wat dié skrywer gebruik het, is egter vir die leser 'n verstaansbelemmering:

"Die huisgesin fundeer in bloedverwantskap op grond van die lede daarvan se genetiese verbondenheid as gevolg van die biotiese lewewekking (kinders) wat basies dan van huis uit familieskap konstitueer. Maar 'n gesin word as sodanig eers deur die liefdesband werklik as 'n egte, per definisie ideale, gesin gekwalifiseer."

'n Volgende skrywer wou waarskynlik sê dat tieners dikwels lui is en liewer passief sou wou sit as om aan sport of liggaamlike oefening deel te neem. Dit is dan die ouer se plig om hierdie tieners aan te moedig om 
liggaamlik te ontwikkel deur byvoorbeeld aan sport deel te neem. Die formulering wat die artikelskrywer gekies het, het die saak egter onnodig ingewikkeld gestel:

"Die ouer moet die onontslote adolessent wat na 'n sedentêre bestaanswyse neig, liefdevol begelei tot die hoogste moontlike vlak van motoriese geskiktheid."

- Dit is die kenmerk van 'n meester dat hy ingewikkelde stof op 'n bevatlike wyse kan deurgee.

- Onduidelike en onhelder formulering is dikwels 'n teken dat die outeur nog nie self die feite genoegsaam verteer het om dit verstaanbaar weer te gee nie. Alvorens jy nie self duidelikheid het oor wat jy wil sê nie, kan jy dit gewoon nie noukeurig onder woorde bring nie.

- Gee jou artikel vir 'n kollega om te lees. Gee dit ook vir iemand wat 'n oningewyde in jou vakgebied is - albei moet in staat wees om die hooflyn van die argument te kan volg, al is die oningewyde nie volledig bekend met die vakjargon nie.

- Verduidelik vakterme - moenie aanvaar dat dit vir jou leser bekend gaan wees nie.

- As jy byvoorbeeld 'n hoofstuk uit 'n verhandeling vir 'n artikel verwerk, moet nie van die leser verwag om die voorkennis van die voorafgaande hoofstukke van jou verhandeling te hê nie. 'n Individuele artikel moet op sy eie pote kan staan en homself as selfstandig, geloofwaardig en oortuigend aandien.

\subsection{Spesifieke aspekte waarna opgelet kan word}

\subsubsection{Sinne wat te swaar dra aan hulle eie bagasie}

Hiermee bedoel ek stellings wat so oorgedokumenteer word dat 'n leser die sinsfokus heeltemal verloor.

Die aangehaalde formulering wat hieronder afgedruk word, is formeel "korrek", maar lees so moeilik dat dit die leser uiteindelik verwar. Ook die feit dat al hierdie inligting in slegs een sin gegee word, veroorsaak 'n leesbelemmering.

\section{Oorspronklike formulering:}

Daar is inderdaad ook ' $n$ geleidelike progressie by die sentrale, naamlose vrouepersonasie in al die verhale teenwoordig, vanaf verliefde, naïewe meisie ("Conversation piece" [p. 18], "Dansmaat" [p. 24] en "Die maaltyd" [p. 27]) en onskuldige slagoffer van geweld ("Die familiefees" [p. 12]) tot ongelukkig getroude vrou ("Die 
Rachelsporsie" [p. 37] en "Die gesprek" [p. 42]), tot geskeide vrou ("Dulle Griet" [p. 48], "Onder 'n skuilnaam" [p. 52] en "COMMAND: COPY DELETE..." [titel deur my verkort, p. 64]), tot lesbiër, molesteerder, moordenaar en prostituut ("Die medleys, intussen, het opgehou swem" [p. 81], "Coitus interruptus" [p. 85], "Uit twee rigtings" [p. 87] en "Poison" [p. 92]).

\section{Geredigeerde weergawe}

In die geredigeerde weergawe wat uiteindelik gepubliseer is, moes noodgedwonge van voetnote gebruik gemaak word, maar dit het waarskynlik die leesproses vergemaklik. Die oorspronklike lang sin is ook onderverdeel in twee sinne.

Daar is inderdaad ook ' $n$ geleidelike progressie by die sentrale, naamlose vrouepersonasie in al die verhale teenwoordig: vanaf verliefde, naïewe meisie ${ }^{1}$ en onskuldige slagoffer van geweld ${ }^{2}$ tot ongelukkig getroude vrou ${ }^{3}$. Hierdie lyn word ook verder voortgesit vanaf geskeide vrou $\mathbf{4}$ tot lesbiër, molesteerder, moordenaar en prostituut 5 .

Inligting wat in die geredigeerde weergawe in voetnote gegee is:

1 "Conversation piece" (p. 180), "Dansmaat" (p. 24) en "Die maaltyd" (p. 27).

2 Kyk "Die familiefees" (p.12).

$3 \quad$ Kyk "Die Rachelsporsie" (p. 37) en "Die gesprek" (p. 42).

$4 \quad$ Kyk "Dulle Griet” (p. 48), "Onder 'n skuilnaam" (p. 52) en "COMMAND:

COPY DELETE ..." (titel verkort; p. 64).

$5 \quad$ Kyk "Die medleys, intussen, het opgehou swem" (p. 81), "Coitus interruptus" (p. 85), "Uit twee rigtings" (p. 87) en "Poison" (p. 92).

\subsubsection{Te veel inligting in een lang sin saamgetrek}

\section{Voorbeeld 1:}

"Hoewel daar nie statistieke oor die buite-egtelike geboortes in die swart stedelike gebiede bestaan nie, blyk die voorkoms van buiteegtelikheid duidelik uit die gesinstrukture soos in 'n onlangse opname onder 1300 swart gesinne in stedelike gebiede waar die enkel-ouergesin en die vrou-kindgesinstruktuur met die vrou as hoof van die gesin met $25 \%$ heel meeste onder die swart mense voorkom."

Weer eens: die sin is nie "verkeerd" nie, maar as dit in meer sinne verdeel sou gewees het, sou dit makliker kon lees. Hierdie een sin kon byvoorbeeld in ses sinne verdeel gewees het:

- Hoewel daar nie statistiek oor buite-egtelike geboortes in swart stedelike gebiede bestaan nie, vertoon stede 'n duidelike voorkoms van buite-egtelikheid. 
- 'n Opname is onlangs onder 1300 swart gesinne in stedelike gebiede gedoen.

- Uit hierdie opname het dit geblyk dat buite-egtelikheid binne spesifieke gesinstrukture voorkom.

- Van die gesinstrukture waarbinne buite-egtelikheid 'n kenmerk is, is die enkelouergesin en die vrou-kindgesinstruktuur duidelik uitgewys.

- Binne hierdie gesinstrukture is die vrou in $25 \%$ van die gevalle die gesinshoof.

- Ook was dit opvallend dat die vrou as gesinshoof 'n verskynsel is wat die heel meeste onder swart mense aangetref word.

\section{Voorbeeld 2}

Let op hoe die sinsvloei belemmer kan word indien inligting te gekonsentreerd gegee word.

\section{Ongeredigeerd}

"As die bewindstydperke van opeenvolgende Israelse eerste Ministers en hulle hantering van die Palestynse kwessie bekyk word, is dit gou duidelik dat die politieke en algemene suksesse van diegene wat as hawks (militaristies georiënteerd, meer ingestel op geweld, onwrikbare onderhandelinstyl) beskryf sou kon word, nie beter is as die doves (plaas nie so 'n hoë premie op militêre geweld nie, verkies onderhandelinge, geneig tot groter billikheid) s'n nie."

\section{Geredigeerd}

Die toeligting wat oorspronklik in die een sin geïnkorporeer was, is in onderstaande paragraaf in 'n aparte sin gestel. Ook is 'n ruspouse in die vorm van 'n dubbelpunt in die eerste sin ingevoeg:

As die bewindstydperke van die Israelse eerste ministers wat mekaar opgevolg het, asook hulle hantering van die Palestynse kwessie bekyk word, is die volgende gou duidelik: die politieke en algemene suksesse van diegene wat as die sogenaamde hawks beskryf sou kon word, is nie beter as dié van die sogenaamde doves nie. (Die hawks is naamlik militaristies georiënteerd, meer ingestel op geweld as politieke instrument en het 'n onversetlike onderhandelingstyl. Die doves plaas nie so 'n hoë premie op militêre geweld nie, verkies onderhandelinge en is geneig tot groter billikheid.)

\subsubsection{Uitasemsinne}

Hierdie tipe sinne vermoei die leser en behoort weer bedink te word. Probeer verhoed dat jy jouself as 't ware in die rede val met addisionele inligting. Sulke onderbrekings strem die sinsvloei. 


\section{Voorbeeld}

"Daar was teen dié tyd 'n veel breër laag van ontwikkelde Afrikaanssprekende lesers as vroeër. Hulle het 'n behoefte gehad aan iets meer as onderhoudende vermaak, hoe knap en geestig dit ook al was, 'n behoefte wat hulle - veral diegene met gevorderde studie, in baie gevalle elders in die wêreld opgedoen - bevredig gekry het in ander tale, veral Engels, en wat hulle ook in hul eie letterkunde en denke oor die letterkunde - maar ook oor meer as dié - gesoek het."

\subsubsection{Opstapelingtegniek wat oordryf word}

Artikelskrywers begin 'n sin dikwels met 'n soort "sambreelfrase" of -sin as inleiding en gebruik dan 'n hele aantal uitbreidings van die aanvanklike gedagte. Hierdie uitbreidings sluit by die inleidende gedeelte aan en moet dit as 't ware voltooi. Formeel is dit nie verkeerd nie, maar daar is sekere slaggate: as die sambreelfrase of -sin nie die heeltyd in gedagte gehou word nie, kan dit lei tot onder andere woordordesteurings.

\section{Voorbeeld:}

Deur sy verwoestingswerk poog Satan daagliks om

- sy eie koninkryk op aarde te vestig;

- Gods kinders afvallig te maak;

- te verhoed dat die Verlosser gebore word;

- die Koning van sy onderdane te beroof;

- die herstel van die skepping te voorkom;

- Satan wil 'n houvas op die gelowige te verkry;

- hy poog om die versoeningslyn deur te sny.

As ' $n$ mens na hierdie voorbeeld kyk, is dit duidelik dat die woordordepatroon tot by frase 5 volgehou is, maar daarna is die bewoording van die inleidende gedeelte vergeet. Dit is ook vir 'n leser moeilik om sulke sinsvoltooiings altyd eers weer saam met die inleidende gedeelte te lees ten einde die sin enduit te volg.

\subsubsection{Varieer die sinskonstruksies}

In plaas daarvan om te sê: "Die Satan vestig sy eie koninkryk op aarde. Hy probeer verhoed dat die Verlosser gebore word. Die Satan probeer om die verlossingslyn deur te sny", varieer die sinne om eenselwigheid te voorkom, byvoorbeeld: 
Deur sy verwoestende werk poog Satan daagliks om sy eie koninkryk op aarde te vestig. Ook wil hy verhoed dat die Verlosser gebore word. Die deursny van die verlossingslyn bly die einddoel van Satan se vernietigingswerk.

\subsubsection{Oorweeg verskillende woordkeusemoontlikhede}

'n Skrywer val soms vas in sy voorkeur vir dieselfde woord, maar veral in geskrewe vorm werk dit eentonigheid in die hand. 'n Werkwoord soos volbring kan byvoorbeeld afgewissel word met die volgende, afhangende van die sinskonteks: voltooi, afhandel, afrond, voleindig, volvoer, bereik.

In hierdie verband kan ook onthou word dat die eenvoudigste woordkeusemoontlikheid dikwels die mees aangewese keuse is. Vergelyk byvoorbeeld die volgende sinne:

God het die aarde gekreëer

God het die aarde geskape

God het die aarde geskep

God het die aarde gemaak

\subsubsection{Aanhalings wat nie funksioneel geïntegreer is nie}

In die onderstaande voorbeeld het die skrywer aanhalings uit verskillende tale saamgebondel. Nie alleen is die lees van so 'n stuk moeilik nie; die deurmekaargooi van verskillende tale is ook redelik "onverteerbaar". Die artikelskrywer kon ewe gemaklik die meeste van hierdie frases in sy eie woorde gestel het.

(Vir die doeleindes van hierdie voorbeeld is die oorspronklike outeursname vir die bronverwysings verander.)

\section{Ongeredigeerde weergawe}

"Geloof is 'in principle something fixed and definite'. Daar is nie iets soos 'vague and indefinite faith' nie (Bron A, 1987:23). Werklike geloof wat mense tot ' $n$ kerk saambind, is iets anders 'dan ja zeggen op de leer van de kerk of instemming betuigen met de inhoud van de Bijbel' (Bron B, 1976:43). Die Twaalf Artikels is dus as 'Glaubensbekenntnis als die formelhafte zusammenfassen des christlichen Glaubens' en 'die Richtsnur des Glaubens' (Bron C, 1981:56) saam met die Wet en die Kategismus gebruik. So het die Twaalf Artikels 'gleichsam das zweite Dogma der Kirche' (Bron C, 1981:58) geword. In die krisis van 'n ingrypende reformasie kon gewone mense die belydenisskrifte in 'a popular movement' gebruik om geloof 'from individual, from one family and community to another' (Bron A, 1987:32) uit te dra". 
- Vermy dit ook om so in oorvloed aan te haal. Jou bladspieël lyk naderhand soos 'n speldekussing van al die aanhalingstekens en jy frustreer jou leser.

\subsubsection{Lomp en omslagtige sinskonstruksies}

In onderstaande voorbeeld het die sin so uitgebrei geraak dat sinsdele wat bymekaar hoort, geskei geraak het en sodoende is die sin se vloei en betekenis belemmer.

"Meganisasie en outomatisasie kan ook werkhumaniserend van aard wees. Die grassnyeroperateur van die Plaaslike Owerheid se werk is byvoorbeeld deur middel van 'n waentjie, waarop die operateur staan, wat agter aan 'n selfaangedrewe grassnyer gehaak word, gehumaniseer omdat dit die fisiese vermoeienis van die operateur verminder en produktiwiteit verhoog."

\section{4. 'n Paar spesifieke jakkalsies in die wingerd 'n Paar moenies}

- "Dit": Moenie 'n sin met "Dit" begin nie. Hierdie "Dit" verwys gewoonlik terug na 'n gedagte wat in die vorige sin of sinne gebruik is. Jy as skrywer weet presies waarna hierdie "Dit" verwys. Jou leser moet dikwels raai of kan die verkeerde afleiding maak. Herhaal of omskryf eerder die woord of begrip waarna hierdie "Dit" terugverwys.

- "Dus": Vermy dit om die woord "dus" te dikwels te gebruik. Dus dui gewoonlik op 'n gevolgtrekking wat gemaak word. En jy kan gewoon nie vyf gevolgtrekkings in een paragraaf maak nie.

- Moenie die passiewe vorm van die werkwoord onnodig gebruik nie. In plaas om te sê "Ons word deur die kruisdood van Christus gered, sê gewoon: "Christus red ons deur sy kruisdood".

- Let op dat die betreklike voornaamwoord "waf" nie in die verkeerde sinsposisie gebruik word nie - dit moet liefs direk na die woord waarop dit betrekking het, gebruik word:

\section{Voorbeeld:}

"Die versoening is reeds in sig, wat Christus vir ons bewerk het", in plaas van: "Die versoening wat Christus vir ons bewerk het ...".

- Waak daarteen om onversoenbare woorde saam in 'n sin te gebruik: Voorbeeld 1:

"Die hoogtepunt van Christus se lyding was die kruisdood", in plaas van "Die dieptepunt van Christus se lyding ...". 


\section{Voorbeeld 2:}

"Die Israel-Palestynse krisis het ' $\mathrm{n}$ bousteen in 'n ontluikende wêreldkrisis geword."

Die woorde "bousteen" en "ontluikend" het albei positiewe konnotasies wat nie tuishoort in die negatiewe konteks van "krisis" nie.

- Vermy 'n "deftige" stelwyse - dit is gewoonlik omslagtig:

\section{Voorbeeld 1}

"Die deklarasie is aanduidend van 'n groeiende bewuswording dat ..."

Die sin kan soos volg gewysig word: "Die verklaring dui op 'n groeiende bewuswording dat ..."

\section{Voorbeeld 2}

"Daar moet prioriteit verleen word aan hierdie krisis met die oog op die bereiking van 'n skikking."

Moontlike wysigings: "Gee prioriteit aan hierdie krisis sodat 'n permanente skikking bereik kan word."

\section{Voorbeeld 3}

"Dit word ter oorweging gegee dat die beste belang van die kind juis verg dat in alle aangeleenthede wat hom/haar raak, 'n deeglike oorweging van al hierdie faktore gemaak moet word."

Moontlike wysiging: "Die beste belang van die kind vereis juis dat hierdie faktore deeglik oorweeg word in alle aangeleenthede wat hom/haar raak."

\section{Samevattend}

Wanneer jy artikel beplan, oorweeg hierdie wenke:

- Hou in gedagte wat 'n spesifieke tydskrif verlang.

- Lees die stylvereistes.

- Laat genoeg tyd vir tegniese afronding.

- Wees noukeurig met bibliografiese gegewens.

- Jy gaan wyd lees oor die artikelonderwerp. Selekteer egter net die mees tersaaklike inligting en moenie in die saamstel van die uiteindelike artikel op allerlei afdraaipaadjies ronddwaal bloot omdat jy interessante inligting wil inkorporeer nie. En as jy sulke inligting in 'n voetnoot wil stel, vra jouself af of dit werklik funksioneel is. 
- Lees jou eie formulering baie krities. Vra jouself af of 'n oningewyde jou beredenering en formulering sal kan verstaan.

- Formuleer so duidelik en so ondubbelsinnig as moontlik.

- Hou die taalregister wetenskaplik, maar formuleer helder en verstaanbaar.

- Bly by die fokus en toespitsingspunt van jou artikel-onderwerp. (Kyk onderstaande addendum.)

Om 'n artikel vir 'n akademiese tydskrif te skryf, is 'n veelfasettige proses. 'n Artikel wat egter goed deurdink, logies gestruktureer en tegnies en taalmatig fyn afgerond is, behoort vir die artikelskrywer 'n prioriteit te wees. "Publikasiegereed" impliseer baie ure se nougesette werk. En vir die leser wat so 'n artikel as 'n verfynde eindproduk onder oë kry, behoort die lees daarvan 'n stimulerende ervaring te wees.

\section{Addendum}

\section{Behou die fokus van die artikel}

Op 'n keer het ek 'n artikel aan 'n keurder gestuur. Dit was 'n swaarwigtige, breedsprakige artikel, vermoeiend wat inhoud en trant betref. Dit was vir die leser moeilik om te besluit wat die outeur eintlik wou sê omdat die artikel nie eintlik 'n spesifieke fokus gehad het nie. $\mathrm{Na}$ 'n ruk het ek hierdie brief van 'n keurder gekry;

Mev. Venter, ek sien hoegenaamd nie kans om hierdie artikel te beoordeel nie. Hier is my motivering:

Die pryswenners onder kunsskilders van die verlede het ons meer as eens getrakteer met massas kos wat uitgebeeld word. As 'n mens voor so 'n skildery staan, vind jou oog nêrens 'n sentrale fokuspunt nie. Jy kan die verskeidenheid eenvoudig nie onder een grondnoemer tuisbring nie. Jy sê vir jouself: Dis tegnies donners goed, maar wanneer gaan ek aan die einde kom van al die informasie waarmee ek gevoer word?

'n Mens kry ongeveer dieselfde ervaring in 'n Barok-kerk. Jy word met 'n spiraalpyler opgesuig na bo, fladder tussen gebeeldhoude engele rond, land in die oorvol koepel tussen heiliges en besluit die geselskap is morbied en gly dan weer met goue ranke na onder om mislik te raak van al die vloerteëlpatrone. Daar is te veel wat ingeneem moet word en daarom word niks geniet nie. Maar dis goed!

Die artikel wat ek moes lees, is ' $n$ uitstalling van geleerdheid in die styl van die agtiende eeu toe hierdie brokaattaal en Kaapse draaie 
nog gepas het. ... Die tema van die artikel kon ek nie volg nie - die styl is net te pretensieus. En die gedistilleerde waarheid is altyd eenvoudig.

\section{Kernbegrippe:}

keuringsprosedure van navorsingsartikels

navorsingsartikels: aanbiedingswyse

teksversorging

\section{Key concepts:}

refereeing process of research articles

research articles: presentation of

text editing 